\title{
Algunos problemas en determinar la prevalencia de la dislexia
}

\author{
Tim R. Miles \\ Chartered Psychologist, FBPsS, Profesor Emérito de la Psicología, \\ Universidad de Gales, Bangor
}

Reino Unido

pss044@bangor.ac.uk 


\section{Resumen}

Cualquier cifra que se mencione en cuanto a la prevalencia de la dislexia depende necesariamente de cómo se define la palabra "dislexia". Es inútil definir la dislexia como "lectura inferior". Lo que interesa a nivel científico es el síndrome específico de la dislexia evolutiva, descrito por Critchley (1970) y otros. En este sentido, surgen dificultades en determinar la difusión de la dislexia por las siguientes razones: (i) la condición se muestra de formas distintas en distintas idiomas; (ii) valoraciones completas, las suficientes para llegar a una medida de la difusión, serían una carga pesada sobre los recursos disponibles; (iii) la situación se complica aún más por la existencia de variantes de la dislexia - ligeros casos que a veces ocurren entre los familiares de los más profundamente afectados. Una investigación que se basó en 8947 niños de diez años, durante un seguimiento de diez años al British Births Cohort Stu$d y$ (1970) sugiere una cifra de 3\% para los casos graves, con otros 6\% si se incluyen todas las variantes y casos marginales. Se deben subrayar las limitaciones de estos cálculos.

Palabras clave: dislexia evolutiva, difusión, problemas

\section{Introducción}

Lógicamente está claro que las cifras sobre la prevalencia de la dislexia están relacionadas con su definición: ninguna cifra de difusión tiene significado a menos que estén concretados los criterios utilizados para determinar su presencia o ausencia.

Una función importante de las definiciones es la clasificadora, y suele ocurrir que para algún propósito específico, una clasificación sirve más que otra. No merece la pena ofrecer una definición de la dislexia a menos que sea una definición que ponga límites útiles - o donde los han dejado otros (o los diccionarios), la definición lexica; o donde delimitan una distinción importante u operativa, la definición "estipuladora".

En el caso de la dislexia, se podría en principio presentar un informe, tipo diccionario, de las maneras de la que se ha utilizado la palabra. Pero desde el punto de vista científico esto tendría poco valor, dada la multitud de maneras en que se ha utilizado el término, sean éstas correctas o incorrectas. 
El reto interesante es considerar dónde se pueden colocar los límites más útiles, o, más vulgarmente, dónde "amontonar" y dónde "dividir". Lo que hace falta es una forma de agrupar los fenómenos que serviría como taxonomía digna o principio clasificador. No resulta ninguna taxonomía si simplemente agrupamos todos los lectores malos, ya que la mala lectura puede partir de muchas causas distintas. Sin embargo, una agrupación con valor científico puede conseguirse si seguimos a Critchley (1970) en considerar como un grupo aparte a los que presentan el síndrome, dislexia evolutiva específica. Los fenómenos que constituyen este síndrome los han descrito muchos autores (por ejemplo Critchley, 1970; Naidoo, 1972; Thomson, 1991; Miles, 1993).

¿Cuáles serían los problemas en determinar la difusión de la dislexia evolutiva específica, en el sentido de Critchley? Nos parece que son tres.

\section{(i) En primer lugar, hay problemas que surgen del hecho de que la dislexia se manifieste de distintas formas en los distintos idiomas.}

Partimos del hecho de que los distintos idiomas del mundo tienen distintos sistemas de escritura. Muchos, aunque no todos, tiene una escritura alfabética, pero hay excepciones, por ejemplo el kanji utilizado en la escritura de palabras chinas y japonesas. Incluso en el caso de los idiomas que utilizan una escritura alfabética, hay distintos grados de regularidad fónica: algunos idiomas - por ejemplo el español, el italiano, y el galés-donde la misma letra del alfabeto constantemente representa el mismo sonido. Esto no es así, sin embargo, con el inglés y el francés. Ya que la dislexia es sobre todo un problema de memorizar y reproducir material simbólico que se les presenta a gran velocidad, conseguir una ortografía correcta en inglés le supone para el alumno enormes dificultades.

En los idiomas fonéticamente regulares, la lectura en sí, hasta para un típico disléxico, no le producirá un problema muy grave. Aprender de memoria las correspondencias letrasonido le puede llevar más tiempo al disléxico, pero su gran ventaja es la coherencia, y cualquier habilidad que se practica con constancia no se le olvidará. Sin embargo, los problemas se dan, no tanto en la misma lectura, sino en la velocidad de la lectura y en aprender de memoria las convenciones de escritura como las marcas diacríticas.

Hoy por hoy no sabemos si las anomalías biológicas que ocurren en los disléxicos son comunes a todos los países del mundo, o si la distribución de estas anamolías varía de de un país a otro. Sin embargo, parece probable que aquél sea el caso, y que las variaciones que 
muestra la dislexia en las distintas partes del mundo dependen de factores ambientales y en particular del sistema de escritura que se utiliza.

A partir de aquí, nos limitamos a las cuestiones pertinentes a la difusión de la dislexia entre los que tiene el inglés como primera lengua.

\section{(ii) Un problema fundamental es el de encontrar los recursos para llevar a cabo valora- ciones de dislexia a gran escala.}

Ilustramos el problema haciendo referencia al seguimiento en 1980 del British Births Cohort Study de 1970, en el que nosotros mismos colaboramos (véase, por ejemplo, Miles, Haslum y Wheeler, 1998). Por lo tanto podemos describir de primera mano algunas dificultades que había que superar. Los niños seleccionados para el estudio fueron los que nacieron en Inglaterra, Gales y Escocia durante la semana del 5 al 11 de abril, 1970. Al principio había más de 14,000 de tales niños, y en el momento del seguimiento en 1980, había datos educativos disponibles para 12.905 niños. Se usaron pruebas convencionales de la lectura, la ortografía y la inteligencia, junto con cuatro ítems de pruebas que creíamos que eran indicadores de la dislexia en el contexto de pésimos niveles de rendimiento en la lectura o la ortografía. (Lo que cuenta como indicador de la dislexia suele depender del contexto en el que ocurre.) Éstos fueron el ítem Recuperación de Dígitos de las escalas British Ability Scales (Elliott, Murray y Pearson, 1979, 1982) y tres ítems de la prueba Bangor Dyslexia Test (Miles, 1982, 1997), a saber: una serie de preguntas que ponen a prueba la conciencia de "izquierda" y "derecha", y una instrucción de enumerar los meses del año, primero en orden del primero al último, y después al revés. Si un niño presentara tendencias disléxicas en al menos dos de estos cuatro ítems, y también tuviera un nivel muy bajo de rendimiento en la lectura o la ortografía, se le consideró como disléxico. De los 12.905 niños del estudio, 3.200 resultaron como de baja capacidad en las pruebas de inteligencia, $y$, aunque por supuesto es posible que un niño de baja capacidad también sea disléxico, decidimos (después de mucha duda) excluir a estos niños de nuestro análisis, por el motivo de que la "baja capacidad" es un factor complicador añadido. Otros 757 se les tuvo que excluir del análisis por datos parciales. Por lo tanto, había datos para un total de 8.947 niños.

En un análisis reciente de nuestros datos (Miles, Wheeler y Haslum 2003), dividimos la cohorte en nueve grupos, creando tres sub-grupos de rendimiento (rendimiento normal; rendimiento medio-bajo, y rendimiento muy bajo), y tres sub-grupos clasificados según el grado de presencia de indicadores de la dislexia (ninguno o pocos indicadores, un número 
reducido, y un número más grande). Los números para cada grupo están presentados en la tabla 1.

Tabla 1. Cantidades en cada uno de los nuevos grupos

\begin{tabular}{|c|c|c|}
\hline $\begin{array}{c}\text { Rendimiento } \\
\text { Normal }\end{array}$ & $\begin{array}{c}\text { Rendimiento } \\
\text { Medio-Bajo }\end{array}$ & $\begin{array}{c}\text { Rendimiento } \\
\text { Bajo }\end{array}$ \\
\hline I. 4998 & II. 1159 & III. 417 \\
\hline IV. 918 & V. 326 & VI. 221 \\
\hline VII. 422 & VIII. 221 & IX. 269 \\
\hline
\end{tabular}

Los grupos I, II y III mostraron pocos o ningún indicador de la dislexia, los grupos IV, V y VI mostraron un número reducido de indicadores de la dislexia, y los grupos VII, VIII y IX mostraron un número mayor.

Se puede observar que el grupo IX lo constituyen los de muy bajo rendimiento que presentan un número mayor de indicadores disléxicos. De hecho había 269 de estos niños, y si sólo se consideraran a estos niños, como disléxico, esto nos daría una cifra de difusión del $3 \%$.

Así que, ¿cuáles eran las dificultades que hacen menos que satisfactorio esta cifra del 3\%? Un problema fundamental estribó en determinar quién era disléxico y quién no. En una valoración de dislexia, la mayoría de los psicológicos administran varias pruebas en un espacio de dos horas o más. Ni siquiera se podrían describir los recursos que serían necesarios para examinar más de 12.000 niños con este nivel de minuciosidad, y tuvimos que limitarnos (véase arriba), incluyendo sólo cuatro ítems que creíamos ser pertinentes a la dislexia-ítems que podrían ser administrados por los profesores de los niños, y que no ocuparían un período de tiempo excesivo.

Lo que más difícil nos resultó fue tener confianza en haber excluído la dislexia. Como se observa en la tabla 1, había 417 niños del grupo III y 221 niños de grupo VI. En ninguno de los dos se pudo discriminar cuáles de las señales aparentemente "positivas" eran auténticos indicadores de la dislexia, y cuáles ocurrían simplemente como parte de la variación normal. Además, podía haber niños del grupo VIII - rendimiento medio-bajo - quienes en realidad eran disléxicos, pero para la edad de 10 años habían aprendido a leer y a escribir a un nivel regular. Por lo tanto, aunque hay cierta confianza que todos o la mayoría de los niños 
del grupo IX eran auténticamente disléxicos, podía haber otros niños disléxicos en algunos otros grupos - no hay manera de asegurarse que la dislexia fuera excluida.

En nuestros trabajos publicados hasta la fecha, hemos afirmado sólo que el grupo III contenía menor proporción de disléxicos que el grupo VI, y una proporción todavía menor que el grupo IX (e igualmente, mutatis mutandis, con los grupos IV, V, VII y VIII); no hemos intentado decir cuáles de los individuos eran disléxicos o cuáles no. Los ítems sobre dislexia han demostrado su valor en que han conducido a predicciones que, sin ellos no se las podría haber hecho. Sin embargo, si uno utiliza estos ítems en un intento de medir la difusión, es importante ser consciente de todas las reservas que hay que tener en cuenta.

(iii) Queda una tercera dificultad con estas cifras, todavía más intratable—la que surge de la existencia de variantes de dislexia.

Hasta donde nosotros conocemos, este problema aún no se ha planteado adecuadamente. Critchley y Critchley (1978, capítulo 9) han hablado de variantes de la dislexia, o formes frustes. En estos casos las manifestaciones se las puede considerar incompletas: puede haber señales secundarias de la dislexia (a veces entre familiares de los más seriamente afectados) pero los individuos bajo consideración no son casos clásicos.

A partir de los datos de la tabla 1, hemos afirmado que tales casos pueden encontrarse en el group VII - aquellos niños que bajo nuestro sistema de puntuación salían con rendimiento normal, pero mostraron un número importante de indicadores positivos en los ítems de dislexia.

En este grupo encontramos un número excesivo de varones, y que sus puntuaciones medias en varias medidas asociadas a la dislexia (incluso la comprensión lectora, lectura de pseudo-palabras, y una prueba matemática) fueron más bajas que los de rendimiento normal del grupo I.

Llamamos 'intratable' a este problema porque no sólo hay una duda sobre la realidad (¿qué habría sido si dispusiéramos de más datos?); sino también una duda conceptual sobre qué combinaciones de respuestas deben contar como manifestaciones de la dislexia. Después de todo, hay muchas maneras distintas de manifestar que una persona sea disléxica; la lista de tales maneras no tiene límite definido. Citando unas palabras de Wittgenstein (1952) dentro de otro contexto, diremos 'No sabemos cuáles son los límites porque no se ha trazado ninguno'. 
Faltando más detalles sobre los niños, y faltando una especificación conceptual adecuada, las conclusiones sobre quiénes en los grupos III, VI, VII y VIII puedan ser disléxicos (sin hablar de los demás grupos), lógicamente no puede apoyarse sobre una base segura. Sin embargo, reconociendo la debilidad de esta base, nos hemos permitido el lujo de alguna especulación. Tal especulación nos puede conducir hacia una conjetura de que la tercera parte de los del grupo III, digamos, 140, la mitad de los del grupo VI, digamos 110, la tercera parte de los del grupo VII, digamos 140, y la mitad de los del grupo VIII, digamos 110, se les podría contar, o como disléxicos, o con manifestación de una variante de la dislexia. Esto nos daría otros 500 casos, o en términos relativos, un poco menos del 6\%.

Por lo tanto, la mejor estimación que podemos hacer sobre la prevalencia de la dislexia en Gran Bretaña sería el 3\% de casos agudos, y otro 6\% de casos leves o de variantes de la dislexia. Sin embargo, quedan muchas dudas.

\section{Referencias}

Critchley, M. (1970). The Dyslexic Child. London: Heinemann Medical Books

Critchley, M. y Critchley, E.A. (1978). Dyslexic Defined. London: Heinemann Medical Books.

Elliott, C.D., Murray, DF.J. y Pearson, L.S. (1979, 1982). The British Ability Sales. Windsor: Nelson- NFER.

Miles, T.R. (1982, 1997). The Bangor Dyslexia Test. Wisbech, Cambs.: Learning Development Aids.

Miles, T.R., Haslum, M.N. y Wheeler, T.J. (1998). Gender ratio in dyslexia. Annals of Dyslexia, 48, 27-55.

Miles, T.R., Haslum, M.N. y Wheeler, T.J. (2001). Mathematical abilities of 10-year-old dyslexic cgildren. Annals of Dyslexia, 51, 299-321.

Miles, T.R., Wheeler, T.J. y Haslum, M.N. (2003). Dyslexia without severe literacy problems. Annals of Dyslexia, 53, 340-349.

Naidoo, S. (1972). Specific Dyslexia. London: Pitman.

Robinson, R. (1950). Definition. Oxford: Oxford University Press. 
Thomson, M.E. (1991). Developmental Dyslexia (3rd ed.) London: Whurr.

Wittgenstein, L. (1952). Philosophical Investigations. (tr. G.E.M. Anscombe) Oxford: Blackwell. 